\title{
Metallic Ion Sensing with a Benzothiazole-Based Fluorimetric Chemosensor ${ }^{+}$
}

\author{
Cátia D. F. Martins, M. Manuela M. Raposo and Susana P. G. Costa * \\ Centre of Chemistry, University of Minho, Campus de Gualtar, 4710-057 Braga, Portugal; \\ catiadf_martins@hotmail.com (C.D.F.M.); mfox@quimica.uminho.pt (M.M.M.R.) \\ * Correspondence: spc@quimica.uminho.pt; Tel.: +351-253-604054 \\ + Presented at the 22nd International Electronic Conference on Synthetic Organic Chemistry, 15 November- \\ 15 December 2018; Available Online: https://sciforum.net/conference/ecsoc-22.
}

Published: 14 November 2018

\begin{abstract}
An unnatural amino acid derivative, $\mathrm{N}$-tert-butyloxycarbonyl asparagine benzyl ester bearing a benzothiazole unit at the side chain, was evaluated as a fluorimetric chemosensor for several transition metal cations with environmental, biological and analytic relevance. Spectrofluorimetric titrations of the heterocyclic asparagine derivative with the various ions were carried out in acetonitrile and acetonitrile/water (9:1). It was found that the unnatural amino acid had a remarkable fluorimetric response in the presence of $\mathrm{Cu}^{2+}$ in acetonitrile and in the presence of $\mathrm{Fe}^{3+}$ in acetonitrile/water (9:1).
\end{abstract}

Keywords: asparagine; benzothiazole; fluorimetric chemosensor; metallic ions

\section{Introduction}

The recognition of metallic ions has been given great attention due to their important roles in many biological and environmental processes that can be followed by fluorimetry [1]. The use of fluorimetry in the qualitative and quantitative determination of such species is considered one of the most effective analytical methods for biomedical and environmental monitoring, allowing fast and sensitive detection, usually with low detection limits which are particularly suitable for dilute media [2].

Recent studies have been carried out in the field of design, synthesis and characterization of novel amino acids (alanines, phenylalanines, asparagines) functionalized with heterocyclic rings (benzoxazole, benzimidazole) and substituents with different electronic character, having in mind the modulation of their photophysical properties and improvement of chemosensory ability [3-5]. These ensembles can be considered as unnatural amino acids, which can act as building blocks for intrinsically-labelled fluorescent peptides with enhanced coordination ability [6]. Also, benzothiazoles are known for displaying high relative fluorescence quantum yields and fine-tuning of the optical properties can be achieved by adequate substituent choice at selected positions of the heterocyclic ring [3].

In this communication, we report the chemosensory ability study of a benzothiazole unit coupled to an amino acid core, with potential application as fluorimetric chemosensor for metallic cations, such as $\mathrm{Cu}^{2+}, \mathrm{Zn}^{2+}, \mathrm{Fe}^{2+}$ and $\mathrm{Fe}^{3+}$. There is an interest in the development of new sensing systems for these cations since they are examples of the most abundant essential elements in the human body and play vital roles in several physiological processes [7-9], along with being widely used in metallurgical, pharmaceutical and agrochemical industries [10]. As a consequence of their wide variety of applications in life sciences and industry, they have become hazardous environmental pollutants [11]. 


\section{Materials and Methods}

\subsection{General}

All reagents and the acetonitrile used in the spectrofluorimetric titration (of spectroscopic grade) were purchased from Sigma-Aldrich, Acros and Fluka and used as received. TLC analysis were carried out on $0.25 \mathrm{~mm}$ thick precoated silica plates (Fertigplatten Kieselgel 60F254, Merck, Darmstadt, Germany) and the spots were visualized under UV light. UV-Visible absorption spectra were obtained using a Shimadzu UV/2501PC spectrophotometer. Fluorescence spectra were collected using a FluoroMax-4 spectrofluorometer.

\subsection{Spectrofluorimetric Titrations}

Solutions of benzothiazolyl-asparagine $3\left(1 \times 10^{-4} \mathrm{M}\right)$ and of the metallic cations under study $(1$ $\times 10^{-2} \mathrm{M}$ ) were prepared in acetonitrile and acetonitrile/water (9:1). Titration of the asparagine with the several metallic cations $\left(\mathrm{Cu}^{2+}, \mathrm{Zn}^{2+}, \mathrm{Fe}^{2+}\right.$ and $\left.\mathrm{Fe}^{3+}\right)$ was performed by the sequential addition of equivalents of metal cation to the asparagine derivative solution, in a $10 \mathrm{~mm}$ path length quartz cuvette and emission spectra were measured by excitation at the wavelength of maximum absorption for compound 3, with a $10 \mathrm{~nm}$ slit.

\section{Results and Discussion}

\subsection{Synthesis of N-tert-butyloxycarbonyl (6-Methoxybenzothiazol-2-yl) Asparagine 3}

Asparagine derivative 3 was obtained from the corresponding N-tert-butyloxycarbonyl asparagine benzyl ester precursor 1 and 2-amino-6-methoxybenzothiazole 2, by a DCC/HOBt mediated coupling in excellent yield of $91 \%$ (Scheme 1). This synthesis was carried out as reported previously by us [3] and the structure of the synthesized compound was confirmed by ${ }^{1} \mathrm{H}$ and ${ }^{13} \mathrm{C}$ NMR spectroscopy.

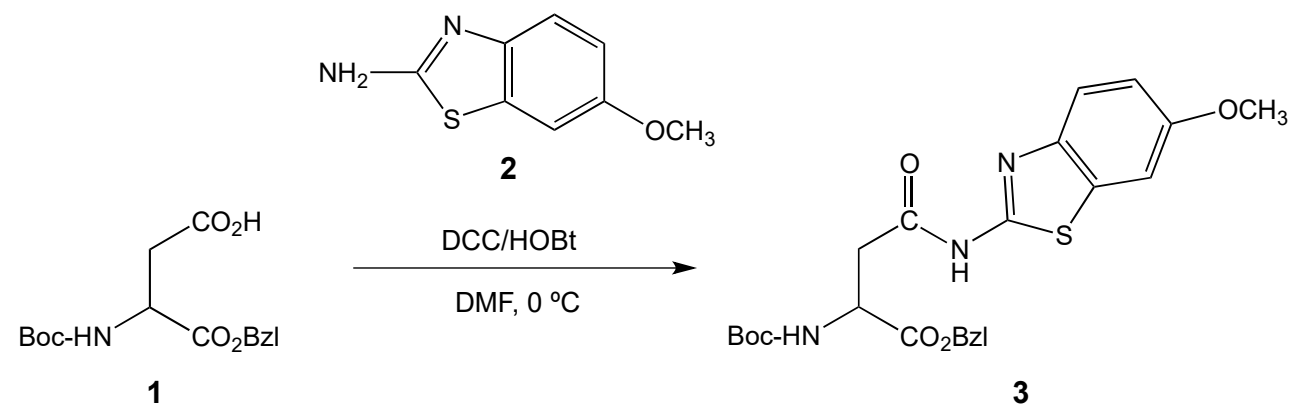

Scheme 1. Synthesis of benzothiazolyl-asparagine 3.

\subsection{Spectrofluorimetric Titrations with Metallic Cations}

The evaluation of benzothiazolyl-asparagine 3 as a fluorimetric chemosensor was carried out by performing spectrofluorimetric titrations in acetonitrile and acetonitrile/water (9:1) in the presence of transition metal cations $\left(\mathrm{Cu}^{2+}, \mathrm{Zn}^{2+}, \mathrm{Fe}^{2+}\right.$ and $\left.\mathrm{Fe}^{3+}\right)$ with biological, environmental and analytical relevance. Acetonitrile was chosen as solvent as it is aprotic and does not interfere by establishing $\mathrm{H}$ bonds with the analyte and/or the sensing system.

The spectral changes, after the addition of increasing amounts of the several ions to a solution of benzothiazolyl-asparagine 3, were evaluated by spectrophotometry and spectrofluorimetry. In the spectrophotometric titrations, no changes were observed in the position or intensity of the absorption band.

However, significant changes could be seen in the fluorescence spectrum of system 3 . In the spectrofluorimetric titrations with $\mathrm{Cu}^{2+}$ in acetonitrile, a strong decrease of the fluorescence intensity was observed for compound 3, with only 1.0 equivalent being necessary to quench $50 \%$ of the initial 
fluorescence. Figure 1 shows the spectrofluorimetric titrations of asparagine 3 with $\mathrm{Cu}^{2+}$, where it was revealed that upon addition of increasing amounts of the cation, the band at $319 \mathrm{~nm}$ decreased drastically, accompanied by the appearance of a red-shifted band at $420 \mathrm{~nm}$ with growing fluorescence intensity that achieved a plateau upon addition of about 20 equivalents of $\mathrm{Cu}^{2+}$ (Figure 1A). There was a similar behaviour in the spectrofluorimetric titrations with $\mathrm{Fe}^{2+}$ and $\mathrm{Fe}^{3+}$; a decrease of the fluorescence intensity was observed at $320 \mathrm{~nm}$, accompanied by an increase in the fluorescence intensity at 435 and $440 \mathrm{~nm}$, respectively. However, the titration with $\mathrm{Fe}^{3+}$ gave an irregular trend of variation (Figure 1B) whereby, in comparison to $\mathrm{Cu}^{2+}$, it was necessary to add a larger amount of $\mathrm{Fe}^{2+}$ (120 equivalents) to achieve a fluorescence plateau at the new red-shifted band, with higher fluorescence intensity (Figure 1C). In the spectrofluorimetric titrations with $\mathrm{Zn}^{2+}$ in acetonitrile, no significant changes were observed with the addition of increasing amounts of this cation, and therefore the heterocyclic asparagine does not behave like a chemosensor for $\mathrm{Zn}^{2+}$ (Figure 1D). From the results obtained, it can be proposed that the synthesized asparagine is a chemosensor for $\mathrm{Cu}^{2+}$ in acetonitrile with high sensitivity.
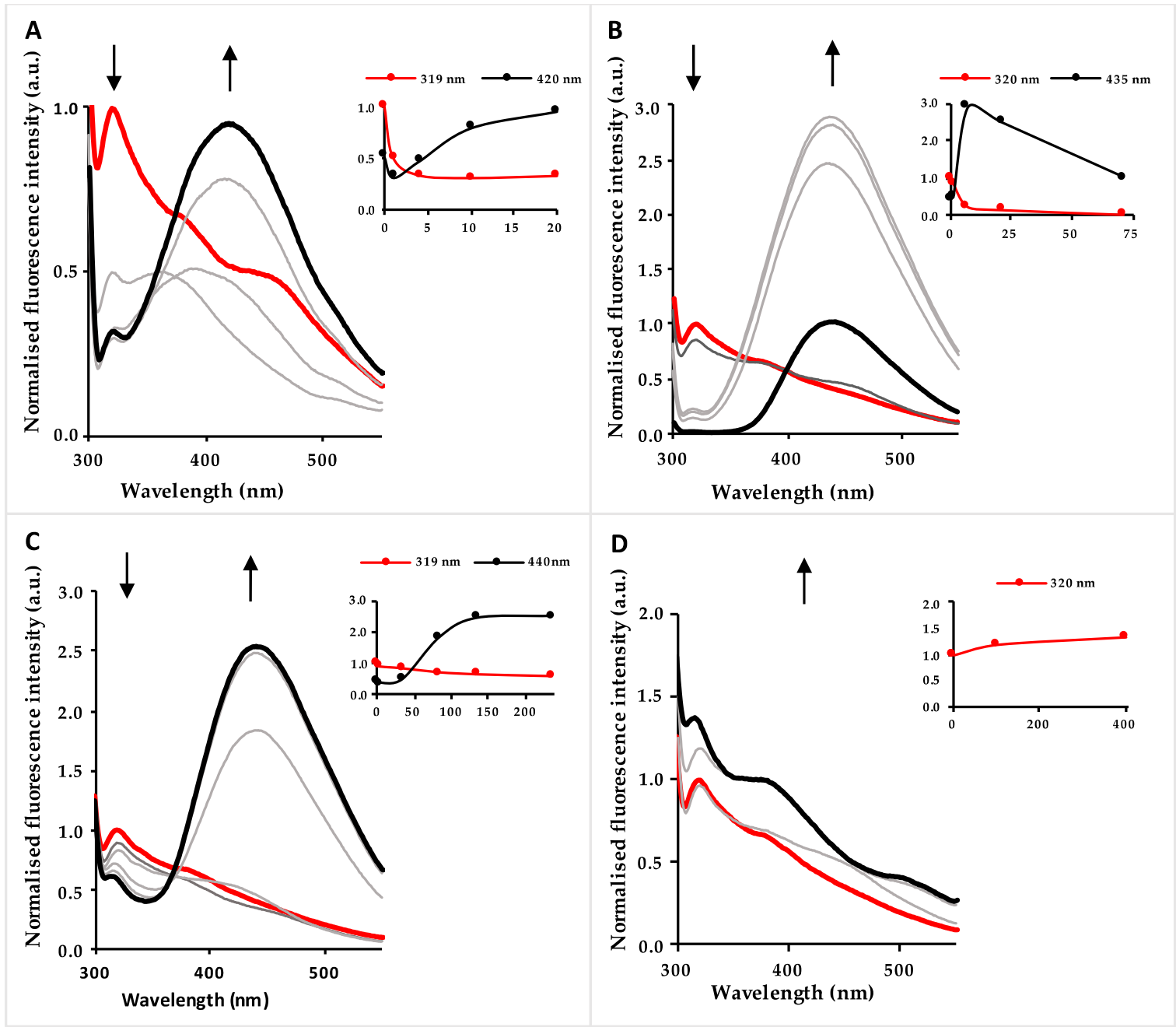

Figure 1. Fluorimetric titrations of benzothiazolyl-asparagine 3 with $\mathrm{Cu}^{2+}(\mathbf{A}), \mathrm{Fe}^{3+}(\mathbf{B}), \mathrm{Fe}^{2+}(\mathbf{C})$ and $\mathrm{Zn}^{2+}(\mathrm{D})$ in acetonitrile $\left(\lambda_{\mathrm{exc}}=290 \mathrm{~nm}\right)$. Inset: normalized emission as a function of added metal equivalents.

Spectrophotometric titrations in the presence of the same transition metal cations were also carried out in acetonitrile and water (9:1), to evaluate their potential application as chemosensors in aqueous environment. These results, when compared to the chemosensing results obtained in acetonitrile solution, revealed that compound $\mathbf{3}$ exhibited a strong decrease in chemosensory ability 
in mixtures of acetonitrile with water in the presence of $\mathrm{Cu}^{2+}$ and $\mathrm{Fe}^{2+}$, with the addition of about 300 equivalents of each cation resulting in a $30 \%$ quenching of the initial fluorescence intensity. For $\mathrm{Zn}^{2+}$, the behaviour was similar to that observed previously in acetonitrile, i.e., no changes were observed upon sequential addition of this cation (Figure 2).

However, in the spectrofluorimetric titrations with $\mathrm{Fe}^{3+}$ in acetonitrile/water (9:1), a steady $\mathrm{CHEQ}$ effect (chelation-enhanced quenching) was observed in the fluorescence spectra. Figure $2 \mathrm{~B}$ shows the spectrofluorimetric titration of asparagine 3 with $\mathrm{Fe}^{3+}$ where it can be seen that, upon addition of 50 equivalents, there was a decrease in fluorescence of circa $75 \%$ of the initial fluorescence intensity at $364 \mathrm{~nm}$. For all other cations tested, no new blue- or red-shifted bands were formed during titration in acetonitrile/water (9:1).
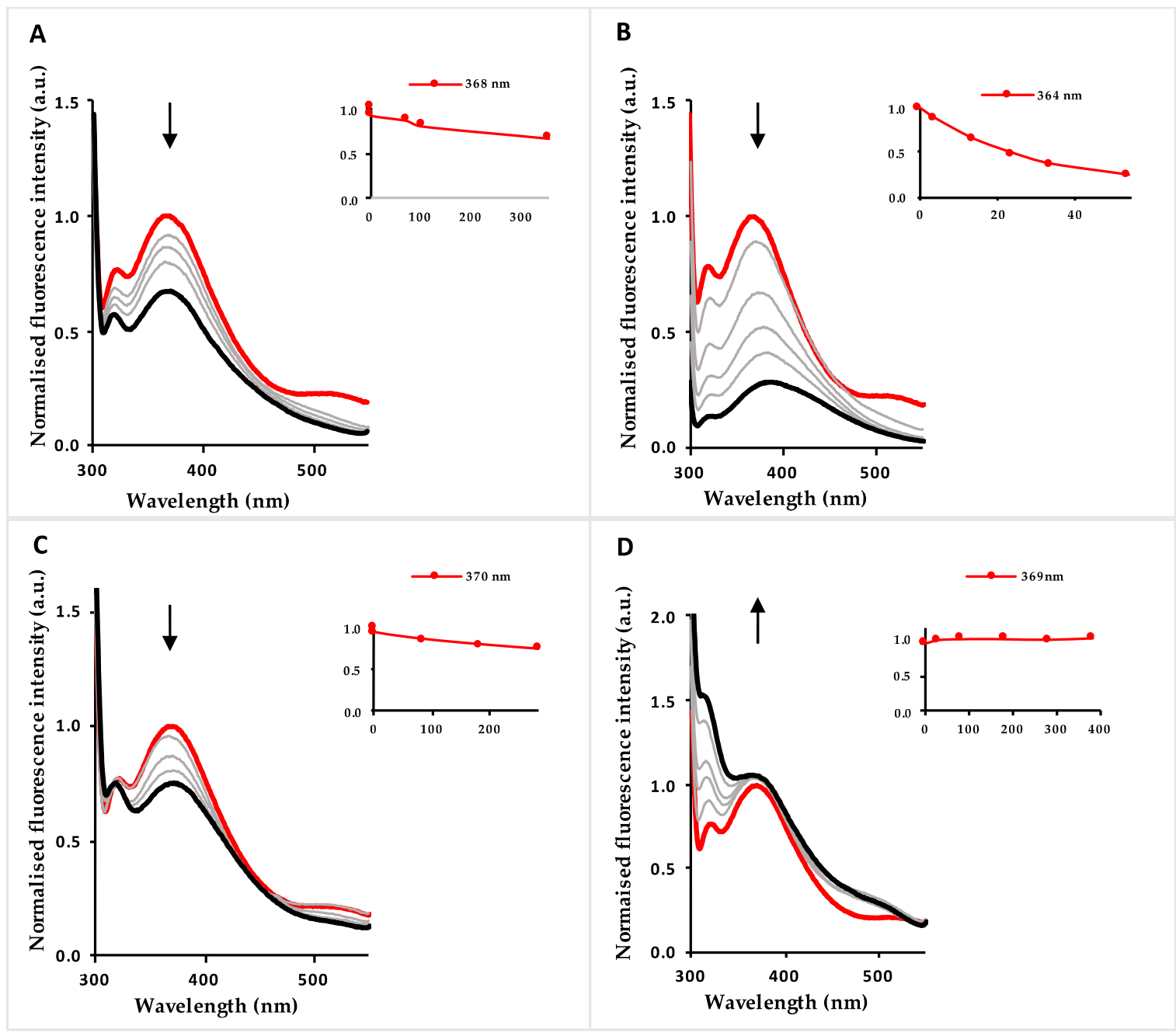

Figure 2. Fluorimetric titrations of benzothiazolyl-asparagine 3 with $\mathrm{Cu}^{2+}(\mathbf{A}), \mathrm{Fe}^{3+}(\mathbf{B}), \mathrm{Fe}^{2+}(\mathbf{C})$ and $\mathrm{Zn}^{2+}(\mathbf{D})$ in acetonitrile/water $(9: 1)\left(\lambda_{\mathrm{exc}}=290 \mathrm{~nm}\right)$. Inset: normalized emission as a function of added metal equivalents.

\section{Conclusions}

Heterocyclic asparagine 3 containing a benzothiazole unit at its side chain was synthesized and evaluated as a fluorescent chemosensor, based on an amino acid core, for a series of relevant transition metal cations $\left(\mathrm{Cu}^{2+}, \mathrm{Zn}^{2+}, \mathrm{Fe}^{2+}\right.$ and $\left.\mathrm{Fe}^{3+}\right)$. From the spectrofluorimetric titrations in acetonitrile, it was found that the tested compound could sense the presence of $\mathrm{Cu}^{2+}$, with a small number of metal equivalents being necessary to achieve a remarkable fluorimetric response. The spectrofluorimetric titrations in acetonitrile/water (9:1) revealed that compound 3 exhibited a decrease in chemosensory ability for $\mathrm{Cu}^{2+}, \mathrm{Zn}^{2+}$ and $\mathrm{Fe}^{2+}$, whereas, in the presence of $\mathrm{Fe}^{3+}$ a strong 
CHEQ effect was observed. The results obtained suggest that this unnatural amino acid can be used for the detection of $\mathrm{Cu}^{2+}$ in acetonitrile and of $\mathrm{Fe}^{3+}$ in acetonitrile/water (9:1) solution.

Acknowledgments: Thank are due to Fundação para a Ciência e Tecnologia (Portugal) and FEDER-COMPETE for financial support through Centro de Química (UID/ QUI/0686/2016).

Conflicts of Interest: The authors declare no conflicts of interest.

\section{References}

1. Rurack, K. Flipping the light switch 'ON'-The design of sensor molecules that show cation induced fluorescence enhancement with heavy and transition metal ions. Spectrochim. Acta Part A 2001, 57, 21612195, doi:10.1016/s1386-1425(01)00492-9.

2. Chowdhury, S.; Rooj, B.; Dutta, A.; Mandal, U. Review on recent advances in metal ions sensing using different fluorescent probes. J. Fluoresc. 2018, 28, 999-102, doi:10.1007/s10895-018-2263-y.

3. Esteves, C.I.C.; Raposo, M.M.M.; Costa, S.P.G. Synthesis and evaluation of benzothiazolyl and benzimidazolyl asparagines as amino acid based selective fluorimetric chemosensors for $\mathrm{Cu}^{2+}$. Tetrahedron 2010, 66, 7479-7486, doi:10.1016/j.tet.2010.07.063.

4. Esteves, C.I.C.; Raposo, M.M.M.; Costa, S.P.G. New 2,4,5-triarylimidazoles based on a phenylalanine core: Synthesis, photophysical characterisation and evaluation as fluorimetric chemosensors for ion recognition. Dyes Pigments 2016, 134, 258-268, doi:10.1016/j.dyepig.2016.07.020.

5. Esteves, C.I.C.; Ferreira, R.M.F.; Raposo, M.M.M.; Costa, S.P.G. New fluoroionophores for metal cations based on benzo[d]oxazol-5-yl-alanine bearing pyrrole and imidazole. Dyes Pigments 2018, 151, 211-218, doi:10.1016/j.dyepig.2017.12.040.

6. Oliveira, E.; Genovese, D.; Juris, R.; Zaccheroni, N.; Capelo, J.L.; Raposo, M.M.M.; Costa, S.P.G.; Prodi, L.; Lodeiro, C. Bioinspired systems for metal-ion sensing: New emissive peptide probes based on benzo[d]oxazole derivatives and their gold and silica nanoparticles. Inorg. Chem. 2011, 50, 8834-8849, doi:10.1021/ic200792t.

7. Kim, H.; Na, Y.J.; Song, E.J.; Kim, K.B.; Bae, J.M.; Kim, C. A single colorimetric sensor for multiple target ions: The simultaneous detection of $\mathrm{Fe}^{2+}$ and $\mathrm{Cu}^{2+}$ in aqueous media. RSC Adv. 2014, 4, 22463-22469, doi:10.1039/c4ra02776k.

8. Pak, Y.; Swamy, K.; Yoon, J. Recent progress in fluorescent imaging probes. Sensors 2015, 15, 24374-24396, doi:10.3390/s150924374.

9. Winter, W.E.; Bazydlo, L.A.L.; Harris, N.S. The molecular biology of human iron metabolism. Lab. Med. 2014, 45, 92-102, doi:10.1309/lmf28s2gimxnwhmm.

10. Jain, A.K.; Singh, R.K.; Jain, S.; Raisoni, J. Copper(II) ion selective electrode based on a newly synthesized Schiff-base chelate. Transit. Met. Chem. 2007, 33, 243-249, doi:10.1007/s11243-007-9022-2.

11. Goswami, S.; Sen, D.; Das, N.K.; Hazra, G. Highly selective colorimetric fluorescence sensor for $\mathrm{Cu}^{2+}$ : Cation-induced "switching-on" of fluorescence due to excited state internal charge transfer in the red/nearinfrared region of emission spectra. Tetrahedron Lett. 2010, 51, 5563-5566, doi:10.1016/j.tetlet.2010.08.048. 